\title{
Clinical validation of implementing Enhanced Recovery After Surgery protocol in elderly colorectal cancer patients
}

\author{
Wooree Koh ${ }^{1}$, Chul Seung Lee ${ }^{1}$, Jung Hoon Bae ${ }^{1}$, Abdullah Al-Sawat ${ }^{2}$, In Kyu Lee ${ }^{1}$, Hyeong Yong Jin ${ }^{3}$ \\ ${ }^{1}$ Division of Colorectal Surgery, Department of Surgery, Seoul St. Mary's Hospital, College of Medicine, The Catholic University of Korea, \\ Seoul, Korea; ${ }^{2}$ Department of Surgery, College of Medicine, Taif University, Taif, Saudi Arabia; ${ }^{3}$ Department of Surgery, Incheon St. Mary's \\ Hospital, College of Medicine, The Catholic University of Korea, Incheon, Korea
}

Purpose: The aim of this study was to evaluate the safety and feasibility of applying Enhanced Recovery After Surgery (ERAS) protocol in elderly colorectal cancer patients.

Methods: The medical records of patients who underwent elective colorectal cancer surgery at our institution, from January 2017 to December 2017, were reviewed. Patients were divided into 2 groups: the young group (YG, patients aged 70 and under 70 years) and the old group (OG, patients over 70 years old). Perioperative outcomes and length of hospital stay were compared between both groups.

Results: In total, 335 patients were enrolled; 237 were YG and 98 were OG. Despite the poorer baseline characteristics of OG, the perioperative outcomes were similar. Length of hospital stay was not different between the groups (YG, 5 days vs. OG, 5 days; $\mathrm{P}=0.320$ ). When comparing the postoperative complications using the comprehensive complication index (CCI), there was no significant difference (YG, $8.0 \pm 13.2$ vs. $\mathrm{OG}, 11.7 \pm 23.0 ; \mathrm{P}=0.130)$. In regression analysis, old age ( $>70$ years) was not a risk factor for high CCI in all patients. In multivariate analysis, C-reactive protein (CRP) level on postoperative day (POD) 3 to 4 was the only strong predictive factor for high CCI in elderly patients.

Conclusion: Implementing the ERAS protocol in patients aged $>70$ years is safe and feasible. High CRP $(\geq 6.47 \mathrm{mg} / \mathrm{dL})$ on POD 3 to 4 can be used as a safety index to postpone discharge in elderly patients.

Keywords: Aged; Enhanced Recovery After Surgery; Colorectal neoplasms; Morbidity

\section{INTRODUCTION}

Enhanced Recovery After Surgery (ERAS) is a multimodal perioperative care protocol designed for quick postoperative recovery $[1,2]$. This protocol reduces surgical stress postoperatively and quickly normalizes the patient's physiological function. As a result, the recovery period is shortened due to improvement in the

Received: Apr 20, 2021 - Revised: May 27, 2021 - Accepted: May 29, 2021 Correspondence to: Hyeong Yong Jin, M.D.

Department of Surgery, Incheon St. Mary's Hospital, College of Medicine, The Catholic University of Korea, 56 Dongsu-ro, Bupyeong-gu, Incheon 21431, Korea

Tel: +82-32-280-5852, Fax: +82-504-468-3796

E-mail: cmcgsjin@gmail.com

ORCID: https://orcid.org/0000-0001-8470-4950

(C) 2022 The Korean Society of Coloproctology

This is an open-access article distributed under the terms of the Creative Commons Attribution NonCommercial License (https://creativecommons.org/licenses/by-nc/4.0) which permits unrestricted noncommercial use, distribution, and reproduction in any medium, provided the original work is properly cited. immunonutritional status, rapid recovery of bowel function, and reduction of pain. According to several previously published randomized controlled trials and meta-analyses reports, ERAS is known to reduce surgical complications and duration of hospital stay [3-6]. Currently, the ERAS protocol is widely adopted, including at our institution, as a standard treatment option for colorectal cancer patients $[5,7]$.

Most colorectal cancers occur in the elderly population $[8,9]$. Elderly patients need more attention due to a number of factors, including a high prevalence of comorbidities, physiological vulnerability, mental disorders, and poor physical function such as sarcopenia [10]. In order to manage these various problems, a multidisciplinary team approach has advantages. However, there is a lack of studies on the outcomes of implementing ERAS protocols in the elderly population. The aim of this study was to evaluate the safety and feasibility of applying ERAS protocol in elderly colorectal cancer patients. 


\section{METHODS}

The medical records of patients who underwent elective colorectal cancer surgery at our institution, from January 2017 to December 2017, were reviewed. All patients implemented the ERAS protocol. A group of 23 interventions was applied in this study based on our previously published protocols (Table 1) [7]. Patients who underwent emergency surgery, stoma closure, or transanal local excision were excluded. Tumor location was defined as the right colon (including the cecum, ascending colon, hepatic flexure, and transverse colon) and left colon (including the splenic flexure, descending colon, and sigmoid colon). Tumors located below the peritoneal reflection were defined as rectal. Cancer obstruction was defined as cancer located in the colon and rectum, unable to pass through the lesion by colonoscopy, or exhibiting obstructive findings on computed tomography.

Patients were divided into 2 groups: the young group (YG, patients aged 70 and under 70 years) and the old group (OG, pa-

Table 1. Enhanced Recovery After Surgery protocol for elective colorectal cancer patients

\begin{tabular}{ll}
\hline Preoperative & \multicolumn{1}{c}{ Protocol } \\
1. Preadmission patient counseling \\
2. Preoperative oral carbohydrate treatment \\
3. Preoperative formula intake \\
4. Thromboembolism prophylaxis \\
5. Prophylactic antibiotics \\
Intraoperative \\
6. Epidural or spinal anesthesia \\
7. Hypothermia prophylaxis \\
8. Restrictive fluid strategy \\
9. Postoperative nausea and vomiting prophylaxis \\
10. Postoperative epidural analgesia \\
11. Multimodal opioid-sparing pain control \\
12. Near-zero fluid balance \\
13. Chewing gum (stimulation of gut motility I) \\
14. Laxative (stimulation of gut motility II) \\
15. Early urinary catheter removal (before postoperative day 3) \\
16. Early surgical drainage removal (before postoperative day 3) \\
17. Termination of intravenous fluid infusion (before postoperative \\
day 3) \\
18. Early mobilization on day of surgery \\
19. Early mobilization on postoperative day 1 \\
20. Early mobilization on postoperative day 2 \\
21. Early mobilization on postoperative day 3 \\
23. Oral intake on postoperative day 1
\end{tabular}

Modified from Kim et al. [7], according to the Creative Commons License. tients over 70 years old). In both of the groups, 237 and 98 patients were registered, respectively (Table 2). Patients' baseline characteristics, perioperative outcomes, length of hospital stay, and readmission rate were collected. We defined readmission as unplanned readmission within 30 days after discharge.

Complications were evaluated using the comprehensive complication index (CCI). CCI is an alternative tool for evaluating complications. CCI was calculated as the sum of the weighted scores according to the Clavien-Dindo classification (CDC) grade and expressed as a score between 0 and 100. Unlike CDC, CCI can also evaluate all minor complications $[11,12]$. CDC grade IIIa or higher is a severe complication that requires intervention, and we

Table 2. Baseline characteristics of the patients

\begin{tabular}{|c|c|c|c|}
\hline Characteristic & $\begin{array}{c}Y G(\leq 70 y r) \\
(n=237)\end{array}$ & $\begin{array}{c}0 \mathrm{G}(>70 \mathrm{yr}) \\
(\mathrm{n}=98)\end{array}$ & P-value \\
\hline Age (yr) & $57.6 \pm 8.7$ & $78.2 \pm 4.7$ & $<0.001$ \\
\hline Sex & & & 0.229 \\
\hline Male & $145(61.2)$ & $53(54.1)$ & \\
\hline Female & $92(38.8)$ & $45(45.9)$ & \\
\hline Body mass index $\left(\mathrm{kg} / \mathrm{m}^{2}\right)$ & $24.1 \pm 3.3$ & $22.9 \pm 3.2$ & 0.003 \\
\hline Smoking & & & 0.001 \\
\hline Yes & 75 (31.6) & $14(14.3)$ & \\
\hline No & $162(68.4)$ & $84(85.7)$ & \\
\hline \multicolumn{4}{|l|}{ Comorbidity } \\
\hline Hypertension & $72(30.4)$ & $52(53.1)$ & $<0.001$ \\
\hline Diabetes & $29(12.2)$ & $24(24.5)$ & 0.005 \\
\hline Cardiovascular & $9(3.8)$ & $10(10.2)$ & 0.021 \\
\hline Cerebrovascular & $2(0.8)$ & $2(2.0)$ & 0.359 \\
\hline COPD & $1(0.4)$ & $3(3.1)$ & 0.043 \\
\hline Hepatitis & $15(6.3)$ & $5(5.1)$ & 0.666 \\
\hline ASA PS classification, $\geq$ III & $4(1.7)$ & $5(5.1)$ & 0.079 \\
\hline Tumor location & & & 0.060 \\
\hline Colon & $162(68.4)$ & 77 (78.6) & \\
\hline Rectum & $75(31.6)$ & $21(21.4)$ & \\
\hline Obstruction & & & 0.443 \\
\hline Yes & $40(16.9)$ & $20(20.4)$ & \\
\hline No & $197(83.1)$ & $78(79.6)$ & \\
\hline Approach & & & 0.147 \\
\hline Laparoscopic & $193(81.4)$ & $86(87.8)$ & \\
\hline Robotic & $35(14.8)$ & $7(7.1)$ & \\
\hline Open & $9(3.8)$ & $5(5.1)$ & \\
\hline Preoperative CRP & $0.7 \pm 1.7$ & $1.0 \pm 2.4$ & 0.196 \\
\hline
\end{tabular}

Values are presented as mean \pm standard deviation or number (\%).

YG, young group; OG, old group; COPD, chronic obstructive pulmonary disease; ASA, American Society of Anesthesiologists; PS, physical status; CRP, C-reactive protein. 
used the CCI score of 26.2, which corresponds to 1 CDC grade IIIa, as the cutoff for high CCI based on prior study [13, 14]. All complications that occurred within 30 days after surgery were recorded. The predictive factors associated with the high CCI $(\geq 26.2)$ group were also analyzed.

This study was approved by the Institutional Review Board of Seoul St. Mary's Hospital, College of Medicine, The Catholic University of Korea (No. KC21RISI0373), and informed consent for an observational study was waived by our institutional policy.

\section{Statistical analyses}

Statistical analysis was performed using IBM SPSS Statistics ver. 24.0 (IBM Corp., Armonk, NY, USA). Fisher exact test was used for categorical data, and the Mann-Whitney U-test was used for continuous data. All analyses were based on available data. Significant associations obtained on univariate analysis were used in a multivariate logistic regression analysis to identify independent predictors of high CCI. Statistical significance was set at $\mathrm{P}<0.05$.

\section{RESULTS}

The patients' baseline characteristics were analyzed for $237 \mathrm{pa}-$ tients in YG ( $\leq 70$ years old) and 98 patients in OG ( $>70$ years old) (Table 2). Body mass index (BMI) was significantly higher in YG $(24.1 \pm 3.3$ vs. $22.9 \pm 3.2, \mathrm{P}=0.003)$ and smoking was significantly higher in YG (75 [31.6\%] vs. 14 [14.3\%]; P=0.001). Patients with underlying diseases such as hypertension, diabetes, cardiovascular disease, and chronic obstructive pulmonary disease (COPD) were significantly higher in the OG group. The proportion of patients with the American Society of Anesthesiologists (ASA) physical status (PS) classification of $\geq$ III was higher in the OG group, but the difference was not statistically significant. There were no differences in tumor location, type of surgery, and preoperative C-reactive protein (CRP) levels between the 2 groups.

Despite the poorer baseline characteristics of OG, the perioperative outcomes were similar (Table 3). The operation time was longer in the YG group $(215 \pm 100.6$ minutes vs. $189 \pm 88.4$ minutes, $\mathrm{P}=0.023)$. Pathological stage, transfusion rate, and postoperative day (POD) 3 to 4 CRP levels were not different between the groups. Median length of hospital stays (YG, 5 days vs. OG, 5 days; $\mathrm{P}=0.320)$ and readmission rates $(\mathrm{YG}, 18$ [7.6\%] vs. $\mathrm{OG}, 4$ [4.1\%]; $\mathrm{P}=0.238)$ did not differ between the groups.

In total, 116 patients (34.6\%) developed postoperative complications. The most common complications were wound complications $(7.8 \%)$ and ileus $(7.2 \%)$. When comparing tumor location, rectal cancer patients showed significantly higher complications rate $(52.1 \%$ vs. $27.6 \%, \mathrm{P}<0.001)$. All of the complication details were described in Supplementary Table 1. The mean CCI for the whole group was $9.1 \pm 16.7$. There was no significant difference in CCI score between both groups (YG, $8.0 \pm 13.2$ vs. OG, $11.7 \pm$ 23.0; $\mathrm{P}=0.130$ ).

The number of patients with low CCI (<26.2) was 297 (88.7\%),
Table 3. Pathologic and perioperative outcomes

\begin{tabular}{|c|c|c|c|}
\hline Variable & $\begin{array}{c}Y G(\leq 70 \text { yr }) \\
(n=237)\end{array}$ & $\begin{array}{c}\mathrm{OG}(>70 \mathrm{yr}) \\
(\mathrm{n}=98)\end{array}$ & P-value \\
\hline TNM stage & & & 0.264 \\
\hline $\mid+\|$ & $115(48.5)$ & $41(41.8)$ & \\
\hline$I I I+I V$ & $122(51.5)$ & 57 (58.2) & \\
\hline Stoma formation & & & 0.057 \\
\hline Yes & $53(22.4)$ & 13 (13.3) & \\
\hline No & $184(77.6)$ & $85(86.7)$ & \\
\hline Other organ resection & & & 0.931 \\
\hline Yes & $33(13.9)$ & $14(14.3)$ & \\
\hline No & $204(86.1)$ & $84(85.7)$ & \\
\hline Operation time (min) & $215 \pm 100.6$ & $189 \pm 88.4$ & 0.023 \\
\hline Transfusion & & & 0.772 \\
\hline Yes & $14(5.9)$ & $5(5.1)$ & \\
\hline No & $223(94.1)$ & $93(94.9)$ & \\
\hline Radical resection & & & 0.471 \\
\hline Ro & $217(91.6)$ & $92(93.9)$ & \\
\hline$\geq \mathrm{R} 1$ & $20(8.4)$ & $6(6.1)$ & \\
\hline CRP POD 3-4 & $7.4 \pm 5.8$ & $7.7 \pm 6.8$ & 0.746 \\
\hline Length of stay (day) & $5(5-7)$ & $5(5-7)$ & 0.320 \\
\hline Readmission & $18(7.6)$ & $4(4.1)$ & 0.238 \\
\hline CCI score & $8.0 \pm 13.2$ & $11.7 \pm 23.0$ & 0.130 \\
\hline
\end{tabular}

Values are presented as number (\%), mean \pm standard deviation, or median (interquartile range).

YG, young group; OG, old group; CRP, C-reactive protein; POD, postoperative day; $\mathrm{CCl}$, comprehensive complication index.

and $38(11.3 \%)$ had a high CCI ( $\geq 26.2)$. In regression analysis, the old age ( $>70$ years) was not a risk factor to high $\mathrm{CCI}$ in all patients (odds ratio [OR], 1.297; 95\% confidence interval [CI], $0.634-2.653 ; \mathrm{P}=0.477$ ) (Tables 4, 5). Subgroup analysis was performed to evaluate the predictive factors of high CCI in each group. In multivariate analysis, high BMI (OR, 3.151; 95\% CI, 1.199-8.276, $\mathrm{P}=0.020)$ and colon obstruction $(\mathrm{OR}, 4.159 ; 95 \%$ CI, 1.429-12.107; $\mathrm{P}=0.009$ ) were strong predictive factors for high CCI in YG. However, in OG, CRP level on POD 3 to 4 (OR, 6.079; 95\% CI, 1.117-33.076; $\mathrm{P}=0.037$ ) was the only strong predictive factor for high CCI.

\section{DISCUSSION}

The population is rapidly aging in the Republic of Korea [15]. Old age, tends to have comorbidities and frailty issues, is associated with increased postoperative complications in patients with gastrointestinal malignancies $[16,17]$. According to literature, early complications after colorectal cancer surgery were seen in $19 \%$ to $40 \%$ of patients $[18,19]$. In this study, overall postoperative com- 
Table 4. Univariate regression analysis for predicting high comprehensive complication index

\begin{tabular}{|c|c|c|c|c|c|c|c|c|c|}
\hline \multirow{2}{*}{ Variable } & \multicolumn{3}{|c|}{ Overall } & \multicolumn{3}{|c|}{$Y G(\leq 70 \mathrm{yr})$} & \multicolumn{3}{|c|}{$\mathrm{OG}(>70 \mathrm{yr})$} \\
\hline & $\mathrm{OR}$ & $95 \% \mathrm{Cl}$ & P-value & $\mathrm{OR}$ & $95 \% \mathrm{Cl}$ & P-value & $\mathrm{OR}$ & $95 \% \mathrm{Cl}$ & P-value \\
\hline Age, $>70 \mathrm{yr}$ & 1.297 & $0.634-2.653$ & 0.477 & & & & & & \\
\hline Sex, female/male & 0.553 & $0.264-1.156$ & 0.115 & 0.717 & $0.296-1.736$ & 0.461 & 0.307 & 0.079-1.195 & 0.089 \\
\hline $\mathrm{BMl}, \geq 25 \mathrm{~kg} / \mathrm{m}^{2}$ & 1.727 & $0.866-3.445$ & 0.121 & 2.505 & $1.084-5.789$ & 0.032 & 0.763 & $0.193-3.013$ & 0.699 \\
\hline ASA PS classification, $\geq$ III & 2.302 & $0.460-11.505$ & 0.310 & 2.903 & $0.290-29.018$ & 0.364 & 1.688 & $0.174-16.393$ & 0.652 \\
\hline Obstruction, yes/no & 3.183 & $1.534-6.607$ & 0.002 & 2.647 & $1.054-6.646$ & 0.038 & 4.347 & $1.268-14.900$ & 0.019 \\
\hline \multicolumn{10}{|l|}{ Approach } \\
\hline Laparoscopic & Reference & & & Reference & & & Reference & & \\
\hline Robotic & 2.290 & $0.960-5.463$ & 0.062 & 2.142 & $0.780-5.882$ & 0.139 & 3.422 & $0.578-20.278$ & 0.175 \\
\hline Open & 3.892 & $1.140-13.287$ & 0.030 & 2.958 & $0.569-15.378$ & 0.197 & 5.704 & $0.838-38.819$ & 0.075 \\
\hline Stomy formation, yes/no & 1.537 & $0.706-3.347$ & 0.279 & 1.403 & $0.553-3.564$ & 0.476 & 2.250 & $0.528-9.584$ & 0.273 \\
\hline Other organ resection, yes/no & 2.115 & $0.930-4.811$ & 0.074 & 2.164 & $0.794-5.898$ & 0.131 & 2.018 & $0.479-8.495$ & 0.338 \\
\hline Operation time & 1.005 & $1.002-1.008$ & 0.001 & 1.006 & $1.003-1.010$ & 0.001 & 1.003 & $0.997-1.009$ & 0.264 \\
\hline Transfusion, yes/no & 3.063 & $1.037-9.045$ & 0.043 & 3.848 & $1.109-13.343$ & 0.034 & 1.688 & $0.174-16.393$ & 0.652 \\
\hline CRP POD 3-4 & 1.148 & $1.088-1.211$ & $<0.001$ & 1.135 & $1.062-1.213$ & $<0.001$ & 1.171 & $1.067-1.285$ & 0.001 \\
\hline
\end{tabular}

YG, young group; OG, old group; OR, odds ratio; Cl, confidence interval; BMl, body mass index; ASA, American Society of Anesthesiologists; PS, physical status; CRP, Creactive protein; $\mathrm{POD}$, postoperative day.

Table 5. Multivariate regression analysis for predicting high comprehensive complication index

\begin{tabular}{|c|c|c|c|c|c|c|c|c|c|}
\hline \multirow{2}{*}{ Variable } & \multicolumn{3}{|c|}{ Overall } & \multicolumn{3}{|c|}{$Y G(\leq 70 \mathrm{yr})$} & \multicolumn{3}{|c|}{ OG (>70 yr) } \\
\hline & $\mathrm{OR}$ & $95 \% \mathrm{Cl}$ & P-value & $\mathrm{OR}$ & $95 \% \mathrm{Cl}$ & P-value & $\mathrm{OR}$ & $95 \% \mathrm{Cl}$ & P-value \\
\hline \multicolumn{10}{|l|}{ Age, $>70 \mathrm{yr}$} \\
\hline Sex, female/male & & & & & & & 0.642 & $0.132-3.119$ & 0.583 \\
\hline $\mathrm{BMI}, \geq 25 \mathrm{~kg} / \mathrm{m}^{2}$ & & & & 3.151 & $1.199-8.276$ & 0.020 & & & \\
\hline \multicolumn{10}{|l|}{ ASA PS classification, $\geq$ III } \\
\hline Obstruction, yes/no & 3.355 & $1.407-7.999$ & 0.006 & 4.159 & $1.429-12.107$ & 0.009 & 4.736 & $0.760-29.501$ & 0.096 \\
\hline \multicolumn{10}{|l|}{ Approach } \\
\hline \multicolumn{10}{|l|}{ Laparoscopic } \\
\hline Robotic & 2.017 & $0.684-5.946$ & 0.203 & & & & & & \\
\hline Open & 1.423 & $0.335-6.056$ & 0.633 & & & & 2.315 & $0.187-28.690$ & 0.513 \\
\hline \multicolumn{10}{|l|}{ Stomy formation, yes/no } \\
\hline Other organ resection, yes/no & 1.045 & $0.361-3.026$ & 0.935 & & & & & & \\
\hline Operation time & 1.284 & $0.527-3.126$ & 0.583 & 2.219 & 0.799-6.164 & 0.126 & & & \\
\hline Transfusion, yes/no & 2.258 & $0.623-8.179$ & 0.215 & 2.802 & $0.713-11.018$ & 0.140 & & & \\
\hline CRP POD 3-4 & 1.756 & $0.804-3.836$ & 0.158 & 0.930 & $0.359-2.411$ & 0.882 & 6.079 & $1.117-33.076$ & 0.037 \\
\hline
\end{tabular}

YG, young group; OG, old group; OR, odds ratio; Cl, confidence interval; BMI, body mass index; ASA, American Society of Anesthesiologists; PS, physical status; CRP, Creactive protein; $P O D$, postoperative day.

plications were seen in 116 patients (34.6\%), and when comparing the 2 groups, YG had 83 patients (35.0\%), and OG had 33 patients $(33.7 \%)(\mathrm{P}=0.900)$. These results were similar to those of a previous study. There was no significant difference between the 2

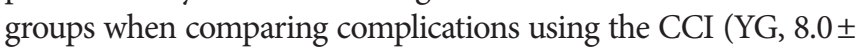

13.2 vs. $\mathrm{OG}, 11.7 \pm 23.0 ; \mathrm{P}=0.130)$. There was no statistical difference in the duration of hospital stay between the 2 groups (YG, 5 days vs. $\mathrm{OG}, 5$ days; $\mathrm{P}=0.320$ ).

Our study validated the clinical usefulness of the ERAS protocol in elderly patients with colorectal cancer. OG patients had poorer 
baseline characteristics, such as a high prevalence of comorbidities (hypertension, diabetes, cardiovascular disease, and COPD) and a high proportion of patients with ASA PS classification of $\geq$ III (Table 2). Despite having more vulnerable factors, the perioperative outcomes were not inferior to those of YG. Several evidence-based studies have demonstrated the ERAS protocol to support body recovery by reducing the stress response during surgery [20]. This finding implies that the ERAS protocol is safe and feasible in elderly patients, and reduction in surgical stress is especially important for elderly patients with many comorbidities and frailties.

Subgroup analysis was performed to determine the factors that influence high morbidity in each group. In multivariable analysis, high BMI and obstructive colon cancer were strong predictive factors for high CCI in the YG. According to many studies, a high BMI $\left(\geq 30 \mathrm{~kg} / \mathrm{m}^{2}\right)$ is highly associated with increased postoperative morbidity, especially surgical site infections [21, 22]. Additionally, obstructive colon cancer has been identified as a risk factor for increased complications [23, 24]. Colon obstruction causes loss of electrolyte and water, often infection, and impedes blood flow to the intestine [25]. Patients with a high BMI or obstructive colon cancer need to be treated more carefully.

CRP is a well-known acute-phase biomarker that can indicate surgical complications [26]. It reached a peak level in the plasma after 48 hours. It can also be used as a marker for infectious complications after surgery. CRP levels were the most accurate on POD 4. In multivariate analysis, OG showed that high CRP $(\geq 6.47 \mathrm{mg} / \mathrm{dL}$ ) on POD 3 to 4 was a significant predictor of severe complications (OR, 6.079; 95\% CI, 1.117-33.076; $\mathrm{P}=0.037$ ). The optimal cutoff value of postoperative CRP was determined by receiver operating characteristic curve analysis. If the CRP level is high on POD 3 or 4, it can be used as a safety index to postpone discharge in elderly patients using the ERAS protocol.

The definition of the elderly varies for each literature, from 65 to 80 years old $[9,27]$. Based on an Italian study [28] that applied the ERAS protocol to high-risk patients and a study to determine the cutoff age related to colorectal cancer-specific survival [29], this study defined the elderly based on the age of 70 years.

This study has several limitations. First, this was a retrospective study. Due to the retrospective design, there was potential bias and missing data in the medical records. Compliance data were not checked thoroughly because it was in the early phase of implementing the ERAS protocol at our institution. Data were not shown due to insufficiency, however, preliminary results showed high compliance rates in both groups (Supplementary Table 2). Future large-scale studies are needed to validate the results of this study. Currently, ERAS protocol items have been added and changed at our institution. Epidural anesthesia was excluded, the surgical drain and urinary catheter were removed earlier, and the oral intake schedule was changed. Further studies are needed to evaluate the differences in the results based on these changes.

In conclusion, age does not affect surgical outcomes in patients with colorectal cancer using the ERAS protocol. Implementing the ERAS protocol in patients aged $>70$ years is safe and feasible without an increase in complications or readmission rates compared to young patients.

\section{CONFLICT OF INTEREST}

No potential conflict of interest relevant to this article was reported.

\section{SUPPLEMENTARY MATERIALS}

Supplementary materials for this study are presented online (available at https://doi.org/10.3393/ac.2021.00283.0040).

\section{REFERENCES}

1. Ljungqvist O. ERAS: enhanced recovery after surgery: moving evidence-based perioperative care to practice. JPEN J Parenter Enteral Nutr 2014;38:559-66.

2. Gustafsson UO, Scott MJ, Schwenk W, Demartines N, Roulin D, Francis N, et al. Guidelines for perioperative care in elective colonic surgery: Enhanced Recovery After Surgery (ERAS ${ }^{\circledR}$ ) Society recommendations. World J Surg 2013;37:259-84.

3. Zhuang CL, Ye XZ, Zhang XD, Chen BC, Yu Z. Enhanced recovery after surgery programs versus traditional care for colorectal surgery: a meta-analysis of randomized controlled trials. Dis Colon Rectum 2013;56:667-78.

4. Feng F, Li XH, Shi H, Wu GS, Zhang HW, Liu XN, et al. Fasttrack surgery combined with laparoscopy could improve postoperative recovery of low-risk rectal cancer patients: a randomized controlled clinical trial. J Dig Dis 2014;15:306-13.

5. Liu VX, Rosas E, Hwang J, Cain E, Foss-Durant A, Clopp M, et al. Enhanced recovery after surgery program implementation in 2 surgical populations in an integrated health care delivery system. JAMA Surg 2017;152:e171032.

6. Greco M, Capretti G, Beretta L, Gemma M, Pecorelli N, Braga M. Enhanced recovery program in colorectal surgery: a meta-analysis of randomized controlled trials. World J Surg 2014;38:153141.

7. Kim MK, Kim JG, Lee G, Won DD, Lee YS, Kye BH, et al. Comparison of the effects of an ERAS program and a single-port laparoscopic surgery on postoperative outcomes of colon cancer patients. Sci Rep 2019;9:11998.

8. Siegel RL, Miller KD, Fuchs HE, Jemal A. Cancer statistics, 2021. CA Cancer J Clin 2021;71:7-33.

9. Papamichael D, Audisio R, Horiot JC, Glimelius B, Sastre J, Mitry E, et al. Treatment of the elderly colorectal cancer patient: SIOG expert recommendations. Ann Oncol 2009;20:5-16.

10. Chia CL, Tan KY. The era of geriatric surgery. Ann Acad Med Singap 2019;48:345-6.

11. Slankamenac K, Graf R, Barkun J, Puhan MA, Clavien PA. The 
comprehensive complication index: a novel continuous scale to measure surgical morbidity. Ann Surg 2013;258:1-7.

12. Kim TH, Suh YS, Huh YJ, Son YG, Park JH, Yang JY, et al. The comprehensive complication index (CCI) is a more sensitive complication index than the conventional Clavien-Dindo classification in radical gastric cancer surgery. Gastric Cancer 2018;21: 171-81.

13. Yamashita S, Sheth RA, Niekamp AS, Aloia TA, Chun YS, Lee JE, et al. Comprehensive complication index predicts cancer-specific survival after resection of colorectal metastases independent of RAS mutational status. Ann Surg 2017;266:1045-54.

14. Tahiri M, Sikder T, Maimon G, Teasdale D, Hamadani F, Sourial $\mathrm{N}$, et al. The impact of postoperative complications on the recovery of elderly surgical patients. Surg Endosc 2016;30:1762-70.

15. Kim KW, Kim OS. Super aging in South Korea unstoppable but mitigatable: a sub-national scale population projection for best policy planning. Spat Demogr 2020;8:155-73.

16. Papamichael D, Audisio RA, Glimelius B, de Gramont A, GlynneJones $\mathrm{R}$, Haller $\mathrm{D}$, et al. Treatment of colorectal cancer in older patients: International Society of Geriatric Oncology (SIOG) consensus recommendations 2013. Ann Oncol 2015;26:463-76.

17. van Gestel YR, Lemmens VE, de Hingh IH, Steevens J, Rutten HJ, Nieuwenhuijzen GA, et al. Influence of comorbidity and age on $1-, 2-$, and 3-month postoperative mortality rates in gastrointestinal cancer patients. Ann Surg Oncol 2013;20:371-80.

18. van der Pas MH, Haglind E, Cuesta MA, Fürst A, Lacy AM, Hop WC, et al. Laparoscopic versus open surgery for rectal cancer (COLOR II): short-term outcomes of a randomised, phase 3 trial. Lancet Oncol 2013;14:210-8.

19. Laparoscopically assisted colectomy is as safe and effective as open colectomy in people with colon cancer (abstracted from: Nelson H, Sargent D, Wieand HS, et al; for the Clinical Outcomes of Surgical Therapy Study Group. A comparison of laparoscopically assisted and open colectomy for colon cancer. N Engl J Med 2004;350:2050-9). Cancer Treat Rev 2004;30:707-9.

20. Ljungqvist O, Hubner M. Enhanced recovery after surgery-
ERAS-principles, practice and feasibility in the elderly. Aging Clin Exp Res 2018;30:249-52.

21. Ozoya OO, Siegel EM, Srikumar T, Bloomer AM, DeRenzis A, Shibata D. Quantitative assessment of visceral obesity and postoperative colon cancer outcomes. J Gastrointest Surg 2017;21:53442.

22. Gurunathan U, Ramsay S, Mitrić G, Way M, Wockner L, Myles P. Association between obesity and wound infection following colorectal surgery: systematic review and meta-analysis. J Gastrointest Surg 2017;21:1700-12.

23. Spannenburg L, Sanchez Gonzalez M, Brooks A, Wei S, Li X, Liang $\mathrm{X}$, et al. Surgical outcomes of colonic stents as a bridge to surgery versus emergency surgery for malignant colorectal obstruction: a systematic review and meta-analysis of high quality prospective and randomised controlled trials. Eur J Surg Oncol 2020;46:1404-14.

24. Cheynel N, Cortet M, Lepage C, Benoit L, Faivre J, Bouvier AM. Trends in frequency and management of obstructing colorectal cancers in a well-defined population. Dis Colon Rectum 2007;50: 1568-75.

25. Yang XF, Pan K. Diagnosis and management of acute complications in patients with colon cancer: bleeding, obstruction, and perforation. Chin J Cancer Res 2014;26:331-40.

26. Messias BA, Botelho RV, Saad SS, Mocchetti ER, Turke KC, Waisberg J. Serum C-reactive protein is a useful marker to exclude anastomotic leakage after colorectal surgery. Sci Rep 2020;10:1687.

27. Robinson TN, Eiseman B, Wallace JI, Church SD, McFann KK, Pfister SM, et al. Redefining geriatric preoperative assessment using frailty, disability and co-morbidity. Ann Surg 2009;250:44955.

28. Braga M, Pecorelli N, Scatizzi M, Borghi F, Missana G, Radrizzani $\mathrm{D}$, et al. Enhanced recovery program in high-risk patients undergoing colorectal surgery: results from the PeriOperative Italian Society Registry. World J Surg 2017;41:860-7.

29. Fu J, Ruan H, Zheng H, Cai C, Zhou S, Wang Q, et al. Impact of old age on resectable colorectal cancer outcomes. PeerJ 2019;7:e6350. 
Supplementary Table 1. Complications in colorectal cancer surgery

\begin{tabular}{|c|c|c|c|}
\hline \multirow{2}{*}{ Complication } & \multicolumn{3}{|c|}{ Tumor location } \\
\hline & Colon & Rectum & Total \\
\hline Wound complication & $11(4.6)$ & $15(15.6)$ & $26(7.8)$ \\
\hline Urinary retention & $5(2.1)$ & $11(11.5)$ & $16(4.8)$ \\
\hline \multicolumn{4}{|l|}{ Bleeding } \\
\hline Intraperitoneal & $2(0.8)$ & $0(0)$ & $2(0.6)$ \\
\hline Intra-luminal & $2(0.8)$ & $1(1.0)$ & $3(0.9)$ \\
\hline Anastomosis leakage & $5(2.1)$ & $10(10.4)$ & $15(4.5)$ \\
\hline Intraperitoneal abscess & $3(1.3)$ & $12(12.5)$ & $15(4.5)$ \\
\hline lleus & $14(5.9)$ & $10(10.4)$ & $24(7.2)$ \\
\hline \multicolumn{4}{|l|}{ Cardiovascular } \\
\hline AMl & $0(0)$ & $0(0)$ & $0(0)$ \\
\hline Arrhythmia & $5(2.1)$ & $2(2.1)$ & $7(2.1)$ \\
\hline PTE & $1(0.4)$ & $1(1.0)$ & $2(0.6)$ \\
\hline DVT & $2(0.8)$ & $0(0)$ & $2(0.6)$ \\
\hline \multicolumn{4}{|l|}{ Pulmonary } \\
\hline Pneumonia & $3(1.3)$ & $3(3.1)$ & $6(1.8)$ \\
\hline ARDS & $1(0.4)$ & $1(1.0)$ & $2(0.6)$ \\
\hline Organ injury ${ }^{\mathrm{a}}$ & $6(2.5)$ & $5(5.2)$ & $11(3.3)$ \\
\hline Others ${ }^{b}$ & $13(5.4)$ & $9(9.4)$ & $22(6.6)$ \\
\hline Total & 66/239 (27.6) & $50 / 96(52.1)$ & 116/335 (34.6) \\
\hline
\end{tabular}

Values are presented as number (\%).

AMI, acute myocardial infarction; PTE, pulmonary thromboembolism; DVT, deep vein thrombosis; ARDS, acute respiratory distress syndrome.

aOrgan injury: other organ injuries like small bowel, duodenum, ascending colon, descending colon, sigmoid colon, liver. ${ }^{b}$ Others include chyle ascites, acute kidney injury, pneumothorax, vulva swelling, non-infected pleural effusion, cerebral infarction, skin rash, gastroesophageal reflux disease, patient-controlled analgesia related headache, epidural site swelling, herpes simplex, cystitis, rectovaginal fistula, and lower extremities weakness. 
Supplementary Table 2. Enhanced Recovery After Surgery (ERAS) compliance

\begin{tabular}{|c|c|c|c|c|}
\hline Variable & Overall $(n=209)$ & $Y G(n=152)$ & $O G(n=57)$ & P-value \\
\hline Mean compliance rate (\%) & 73.4 & 74.0 & 71.7 & 0.298 \\
\hline \multicolumn{5}{|l|}{ ERAS item } \\
\hline Preadmission patient counseling & 193/209 (92.3) & 139/152 (91.4) & $54 / 57(94.7)$ & 0.565 \\
\hline Preoperative oral carbohydrate treatment & 204/209 (97.6) & $147 / 152(96.7)$ & $57 / 57(100)$ & 0.326 \\
\hline Preoperative formula intake & $177 / 209(84.7)$ & 126/152 (82.9) & $51 / 57(89.5)$ & 0.239 \\
\hline Thromboembolism prophylaxis & 198/208 (95.2) & $142 / 151(94.0)$ & 56/57 (98.2) & 0.291 \\
\hline Prophylactic antibiotics & 204/208 (98.1) & $149 / 151(98.7)$ & $55 / 57(96.5)$ & 0.302 \\
\hline Hypothermia prophylaxis & 187/209 (89.5) & 134/152 (88.2) & $53 / 57(93.0)$ & 0.311 \\
\hline Restrictive fluid strategy & 144/208 (69.2) & $107 / 151(70.9)$ & $37 / 57(64.9)$ & 0.407 \\
\hline Postoperative nausea and vomiting prophylaxis & 196/209 (93.8) & $143 / 152(94.1)$ & 53/57 (93.0) & 0.754 \\
\hline Multimodal opioid-sparing pain control & 134/208 (64.4) & $89 / 151(58.9)$ & 45/57 (78.9) & 0.007 \\
\hline Chewing gum (stimulation of gut motility I) & $83 / 171(48.5)$ & $68 / 123(55.3)$ & $15 / 48(31.3)$ & 0.005 \\
\hline Laxative (stimulation of gut motility II) & 191/208 (91.8) & 138/152 (90.8) & $53 / 56(94.6)$ & 0.569 \\
\hline Early urinary catheter removal (before postoperative day 3) & 171/209 (81.8) & 121/152 (79.6) & $50 / 57(87.7)$ & 0.176 \\
\hline Early surgical drainage removal (before postoperative day 3) & $104 / 206(50.5)$ & $75 / 149(50.3)$ & 29/57 (50.9) & 0.945 \\
\hline Termination of intravenous fluid infusion (before postoperative day 3) & 166/208 (79.8) & $118 / 151(78.1)$ & 48/57 (84.2) & 0.331 \\
\hline Early mobilization on day of surgery & 104/174 (59.8) & $80 / 126(63.5)$ & 24/48 (50.0) & 0.105 \\
\hline Early mobilization on postoperative day 1 & $100 / 155(64.5)$ & $81 / 114(71.1)$ & $19 / 41(46.3)$ & 0.005 \\
\hline Early mobilization on postoperative day 2 & $84 / 153(54.9)$ & $70 / 112(62.5)$ & $14 / 41(34.1)$ & 0.002 \\
\hline Early mobilization on postoperative day 3 & $83 / 144(57.6)$ & $64 / 105(61.0)$ & 19/39 (48.7) & 0.187 \\
\hline Oral intake on day of surgery & $57 / 206(27.7)$ & 42/152 (27.6) & 15/54 (27.8) & 0.984 \\
\hline Oral intake on postoperative day 1 & $140 / 208(67.3)$ & $104 / 152(68.4)$ & $36 / 56(64.3)$ & 0.573 \\
\hline
\end{tabular}

Values are presented as percentage only or number (\%).

YG, young group; OG, old group. 